\title{
Percutaneous Fixation of Acetabular Fractures by Columnar Screw
}

\author{
Mohamed S. El-Attar ${ }^{1 *}$, Mohamed Nagy Elalfy ${ }^{2}$, Sherif Aidy ${ }^{3}$ \\ ${ }^{1}$ Lecturer of orthopedic surgery, Zagazig University, Egypt \\ ${ }^{2}$ Lecturer of orthopedic surgery, Zagazig University, Egypt \\ ${ }^{3}$ Lecturer of orthopedic surgery, Zagazig University, Egypt
}

*Corresponding Author: Mohamed S. El-Attar, Lecturer of orthopedic surgery, Zagazig University, Egypt.

\begin{abstract}
Background: The surgical fixation of acetabular fractures using columnar screw technique newly introduced to reduce surgical trauma and blood loss with special care of the indications, skills, and equipment.
\end{abstract}

Patients and Methods: Retrospectively we used percutaneous columnar screw to fix acetabular fractures either non displaced or minimally displaced guided by fluoroscopy. The study included 40 patients with acetabular fractures after obtaining informed consent fixed by anterior column, posterior column, supraacetabular screws, and even combination of plate and screw between June 2016 and June 2020.

Results: All cases had a good to an excellent functional results as regard to the modified Merle d'Aubigné Hip Score. We managed to early mobilization of all patients out of bed post surgery and to avoid a 2 nd approach for transverse fractures by the screw.

Conclusion: Our results show that percutaneous columnar screw with fluoroscopic guidance is a safe technique to treat selected patterns of acetabular fractures and using some tips and tricks in the surgical technique and fluoroscopy time can be minimized.

Keywords: Acetabular fracture - Minimally invasive technique - Percutaneous fixation.

\section{INTRODUCTION}

The goal of fixation of acetabular fractures depends on restoration of articular surface with stable internal fixation, allowing early mobilization of the patient. [1]

The advantage of percutaneous fixation is the immediate stability obtained leading to early mobilization. Other important advantages over open procedures are the decreased operative morbidity, blood loss, time to perform the procedure, wound healing, infection and blood loss and all complications that are more common with open procedure than to the actual fractures. [2]

Where fractures are indicated and/or patients have general condition contra-indicated to major surgery, percutaneous fixation should ideally be indicated. It was found in the early results of many studies that patients had a shorter hospital stay and decreased morbidity using percutaneous techniques for acetabular fractures. [2]

\section{Patients And Methods}

We retrospectively studied 40 cases of our patients operated with percutaneous acetabular screw were done during the period from January 2017 and January 2020 after informed consent for the procedure and for taking intraoperative photos. We collected preoperative, operative and postoperative follow up data and imaging studies from the patient's files and the computerized system and by contacting the patients. We included in the study the forty Patients who regularly follow up with no missing data. Patients who did not show during the follow up or had missing data were excluded from the study. The follow up period was for a minimum of 6 months.

The type of fractures according to tile classification concluded in table 4 .

At the 6 month the modified Merle d'Aubigné hip Scoring system was calculated for evaluation the bony and functional results (Table 1). 
The fracture patterns were either: Nondisplaced (1-3 $\mathrm{mm})$, minimally displaced $(3-5 \mathrm{~mm})$ fractures or displaced both-column or transverse fractures with one column fixed through open reduction and internal fixation throw posterior approach and the other column with percutaneous fixation. [2]

Preoperative planning included $\mathrm{x}$ ray of the pelvis including AP and obturator\& iliac oblique views and CT to properly assess the safety of surgical corridors and intra columnar size for fitting columnar screws. [2, 5]

We used partially threaded $6.5 \& 7.3 \mathrm{~mm}$ cannulated screws with $2 \& 2.8$ guide wire to determine the initial trajectory under fluoroscopic guidance. In obese patients an external fixator sleeve was used to allow proper orientation and directional control and protect soft tissue. [6]

All cases were done under general anesthesia supine position on a flat radiolucent table.

Before patient preparation and draping $\mathrm{C}$ arm views were checked to ensure proper anteroposterior, Judet oblique (iliac \& obturator), pelvic inlet and outlet views. Pelvic region to the umbilicus were draped. For posterior column screw the distal aspect of the ischial tuberosity ensured to have good exposure prior to draping and the patient's hip were checked to ensure hip flexion more than $100^{\circ}$ and abduction without interference. The entire surgical procedure was performed under frequent fluoroscopic control to verify safe screw placement.
We did all anterior column screw in antegrade fashion from the lateral iliac surface with entry point proximal to the acetabulum toward the pubic symphysis. The entry points were located at the junction of a line drawn along the lateral border of the femur through the greater trochanter and a line from the pubic symphysis through the anterior inferior iliac spine (Figure 1). To visualize their trajectory obturator oblique view was used to confirm position of the guide-wire in the superior-inferior plane and an inlet iliac view to confirm position in the antero-posterior plane (Figure 2). [2] When passing along the superior ramus, the passage of the guide wire was followed by flipping between inlet view to assure that no penetration toward the bladder and outlet view to show the superior/inferior pathway of the guidewire (Figure 3). [6]

The retrograde posterior column screw was done with the hip in 120 degree of flexion with flexed knee. The first step was to locate the ischial tuberosity. To help identifying the entry point, an obturator oblique and iliac oblique views were obtained with the hip flexed. This retrograde fixation was carried out under fluoroscopic control with the iliac and obturator oblique views to help guide the wire trajectory in the AP and lateral dimensions (Figure 4). Before fixation, check the hip if there is intraarticular penetration. An obturator oblique view was used to verify the wire trajectory in the AP dimension to avoid wire placement too anteriorly and violating the hip joint or too posterior penetrating to sciatic notch. $[6,7,8]$

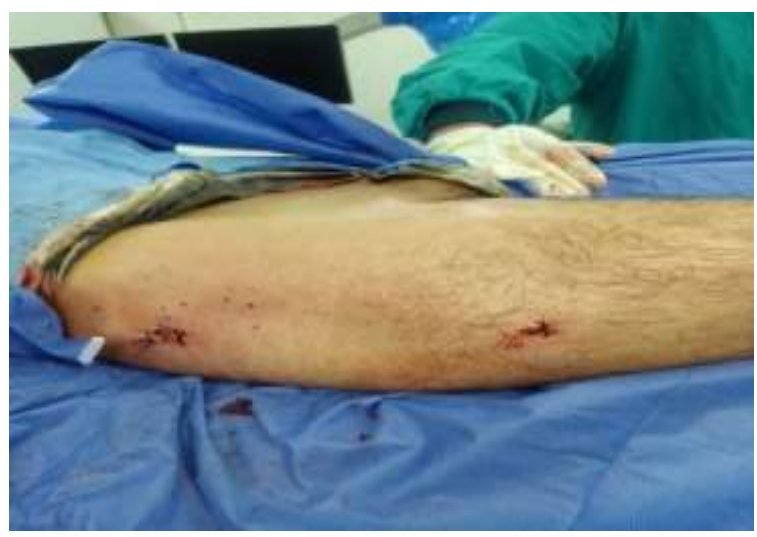

Figure1. Entry point marking on skin for anterior column screw 


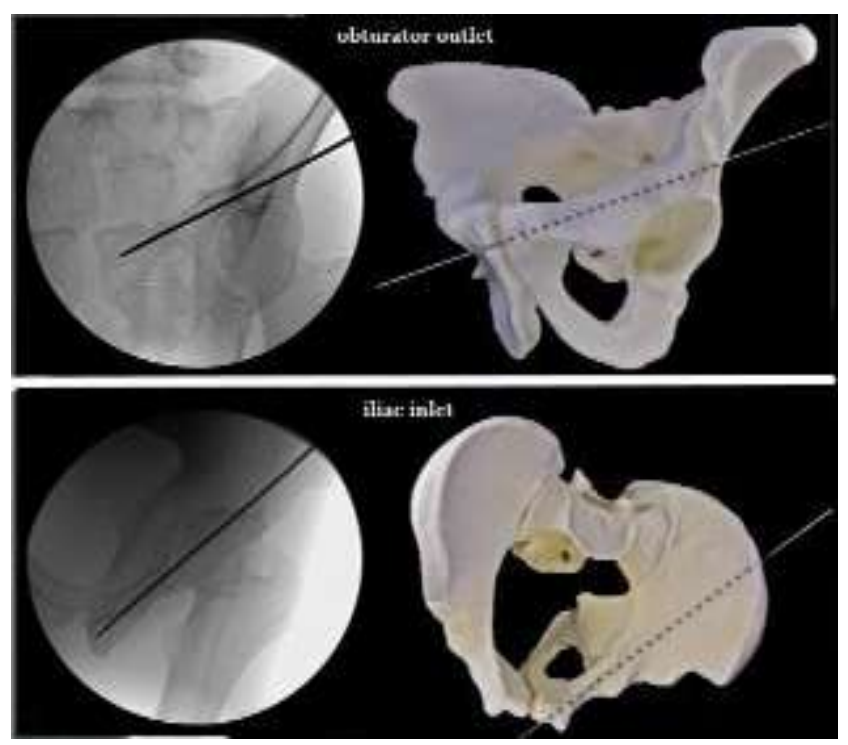

Figure2. Obturator outlet and iliac inlet for anterior column screw

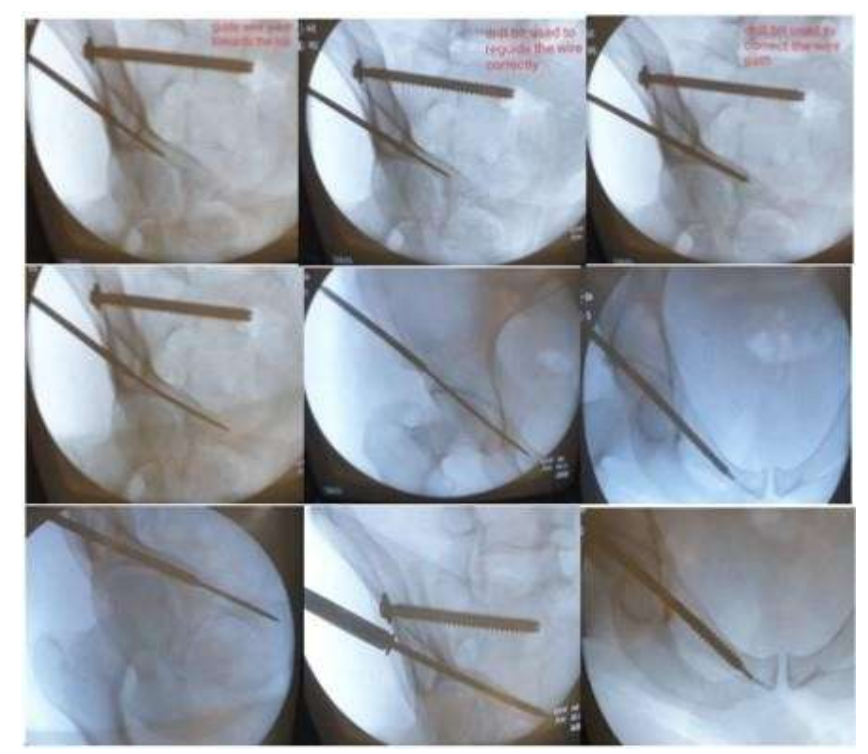

Figure3. Anterior column screw technique

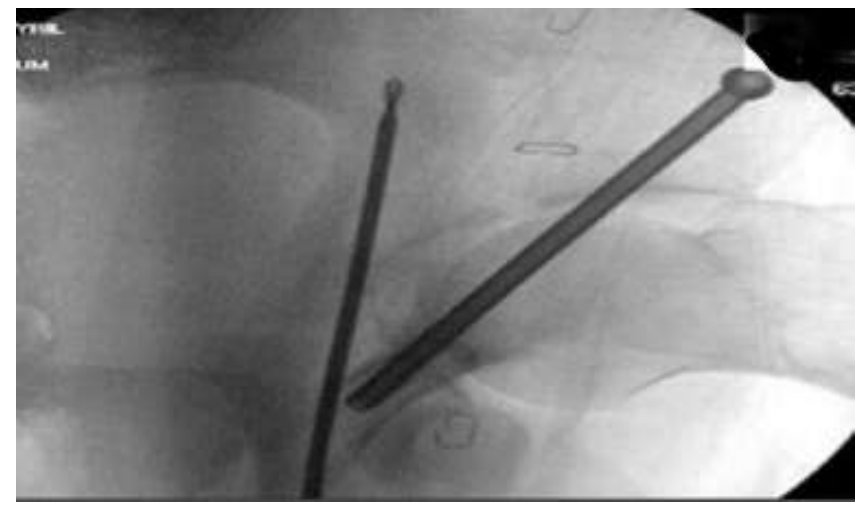

Figure4. Iliac view for posterior column screw

Supra-acetabular Screw was used to secure a fracture involving the supra-acetabular dome. It was inserted from the AIIS toward the PSIS. Entry was adjusted with teardrop view (figure
5). In obese patients or those with obscuring bowel contents a true lateral view was used to show the entry and exit points clearly (figure 6). [9] 


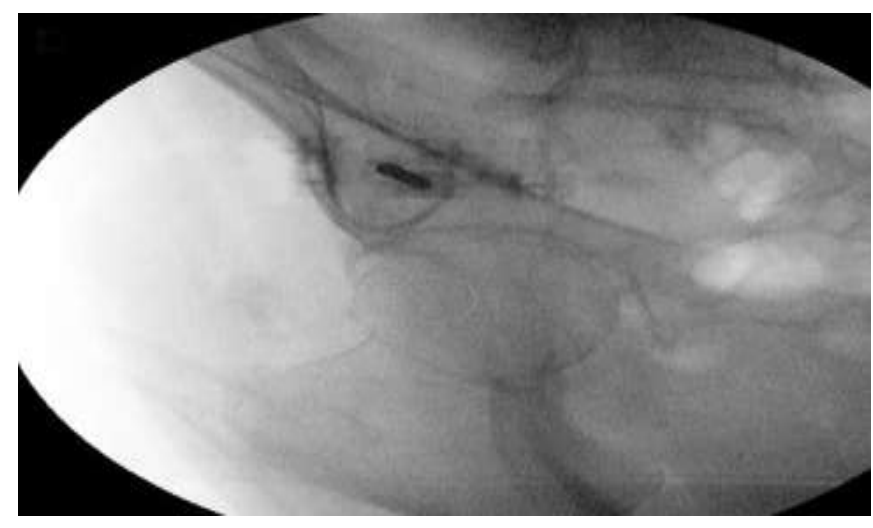

Figure5. Entry point identification by Teardrop view for supraacetabular screw

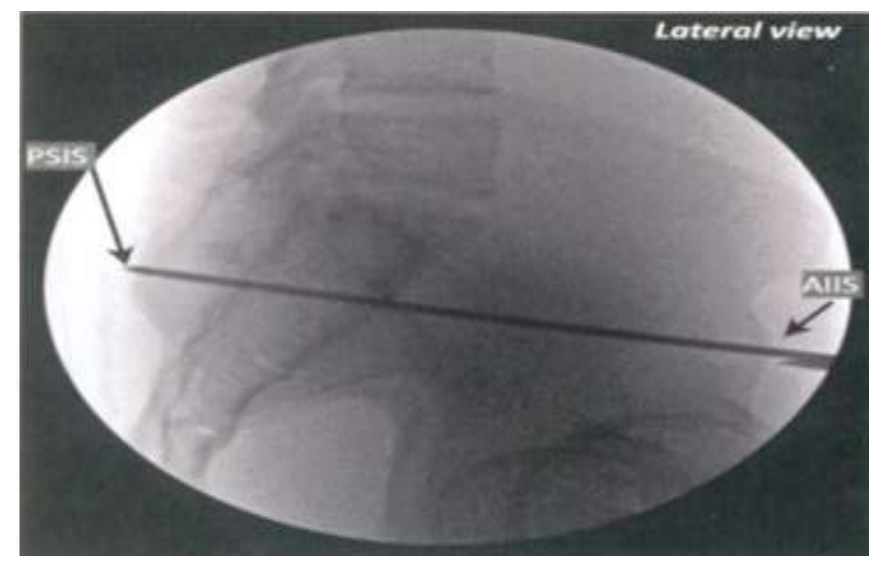

Figure6. True lateral view for supraacetabular screw

\section{Results}

The research was carried out on the 40 patients. Of these, $6(15 \%)$ were females and 34 were males $(85 \%)$. The mean age of the patients was 36 years with the youngest patient being 16 and the oldest 68 years old. The injury mechanism was RTA in 24 patients (60\%) and falling from height in the rest (40\%) (Table 2). 26 patients $(65 \%)$ had isolated acetabular fractures and 14 patients $(35 \%)$ had associated fractures (Table 3). We performed all the operations in supine position. Anterior and supra-acetabular screws were inserted by antegrade technique and posterior screws by retrograde technique.

Table2. Shows the Mode of Trauma and its Frequency

\begin{tabular}{|l|r|r|r|}
\hline \multicolumn{3}{|c|}{ Mode of Trauma } & \multicolumn{2}{|c|}{ Percent } \\
\hline & \multicolumn{2}{|c|}{ Frequency } & 16 \\
\hline Valid & FFH & 24 & 60.0 \\
\hline & RTA & 40 & 100.0 \\
\hline
\end{tabular}

Four patients had bilateral fractures, ten patients had unilateral fracture on the left side and 26 patients had unilateral fracture on the right side. Fracture pattern varied between isolated anterior column (16 patients), isolated posterior column (2 patient), $\mathrm{T}$ type, transverse, transverse with posterior wall, transverse with quadrilateral plate and bi-column fractures (table 4).

Patients were encouraged to ambulate early with toe touch weight bearing as tolerated with a walker or crutches.

We used anterior column screw fixation in 18 patients, posterior column screw in 4 patients, simultaneous anterior and posterior column screws in 10 patients, simultaneous anterior column, supra- acetabular screws in 4 patients, simultaneous anterior column, posterior column and supra-acetabular screws in 4 patients (Table $5)$. 
Table3. Patterns of Associated Injuries and its Frequency

\begin{tabular}{|l|l|c|l|}
\hline \multicolumn{2}{|c|}{ Associated Injury } & Percent \\
\hline Valid & bilatequency femur & 2 & 5.0 \\
\hline & fracture femur + sacroiliac joint & 2 & 5.0 \\
\hline & iliac wing fracture & 2 & 5.0 \\
\hline & None & 26 & 65.0 \\
\hline & Sacroiliac joint & 2 & 5.0 \\
\hline & sacral fracture & 2 & 5.0 \\
\hline & sacroiliac joint & 4 & 10.0 \\
\hline & Total & 40 & 100.0 \\
\hline
\end{tabular}

Table4. Fracture Pattern and its Frequency

\begin{tabular}{|l|l|l|}
\hline \multicolumn{2}{|c|}{ Fracture Pattern } \\
\hline Valid & Ant column fracture & 16 \\
\hline & Bi-column fracture & 4 \\
\hline & Posterior column fracture & 2 \\
\hline & T type fracture & 2 \\
\hline & Transverse + posterior wall & 4 \\
\hline & Transverse + quadrilateral plate & 2 \\
\hline & Transverse fracture & 10 \\
\hline & Total & 40 \\
\hline
\end{tabular}

Table5.Type of Screw Used and Its Frequency

\begin{tabular}{|l|l|l|}
\hline \multicolumn{2}{|c|}{ Type of fixation } \\
\hline \multicolumn{2}{|c|}{ Frequency } \\
\hline Valid & Anterior, posterior \& supra-acetabular screw & 4 \\
\hline & Anterior \& posterior screws & 10 \\
\hline & Anterior \& supra-acetabular screws & 4 \\
\hline & Anterior screw & 18 \\
\hline & Posterior screw & 4 \\
\hline & Total & 40 \\
\hline
\end{tabular}

In 8 patients of 40 the screw was inserted as augmentation to fixation of transverse fracture of the acetabulum, either, plate fixation posterior and percutaneous screw anterior (6 patients) or, plate fixation anterior and percutaneous screw posterior (2 patient).

Operative time for the screw was on average 30 minutes (15 - 45 minutes). The operation time was measured from the first fluoroscopic exposure after patient positioning till the last suture.

We used $6.5 \& 7.3 \mathrm{~mm}$ partially threaded cannulated screws in all patients with average length of $105 \mathrm{~mm}$ for anterior column screw and $125 \mathrm{~mm}$ for posterior and supraacetabular screws.

In all cases, immediate postoperative radiographs and $\mathrm{CT}$ showed that the screws were successfully placed across the fracture line.

Thirty two of our patients were out of bed the second postoperative day. They were allowed toe- touch weight bearing (TTWB) with the aid of a walker. The rest of our patients had to stay in bed or mobilized wheel chair due to bilateral fracture, other comorbidities or fractures. (Table 6)

The average duration of admission for our patients was 8 days. We followed the patients for at least 6 months (average 14 \pm 3.5 month) and in each follow up, we assessed the union, pain, walking ability and return to preoperative activities. The fractures showed union at a mean of 12 weeks postoperatively (range 8-16 weeks).

All the patients without associated fractures could walk fully without any significant pain and had full range of motion of the hip and painless hip movement. 36 patients had normal gate pattern, 4 patients had limping 2 of them because of knee problem associated with the index injury and the other 2 had associated bilateral fracture femur. The 40 patients got back to their preoperative activities. 
The modified Merle d'Aubigné hip score was applied for all patients. The final results after 6 months follow up showed; 26 patients had excellent score and 14 patients had good score. The patients with less than excellent score had either associated fracture in the acetabulum, pelvis or the lower limb.

The radiological results according to union of the fracture were excellent as the all fractures were united without pseudo arthrosis.
The soft tissue dissection was very limited. Four patients had complication of medial cortical pelvic penetration during insertion of posterior column screw with no hazards to the patient and four patients had mild limping after 6 months follow up. None of the patients suffered neurovascular or urinary system injuries related to screw insertion. No infection, bedsores or pulmonary infections or other complicaions (Table 7).

Table6. Post-Operative Physiotherapy in Relation to Associated Injury

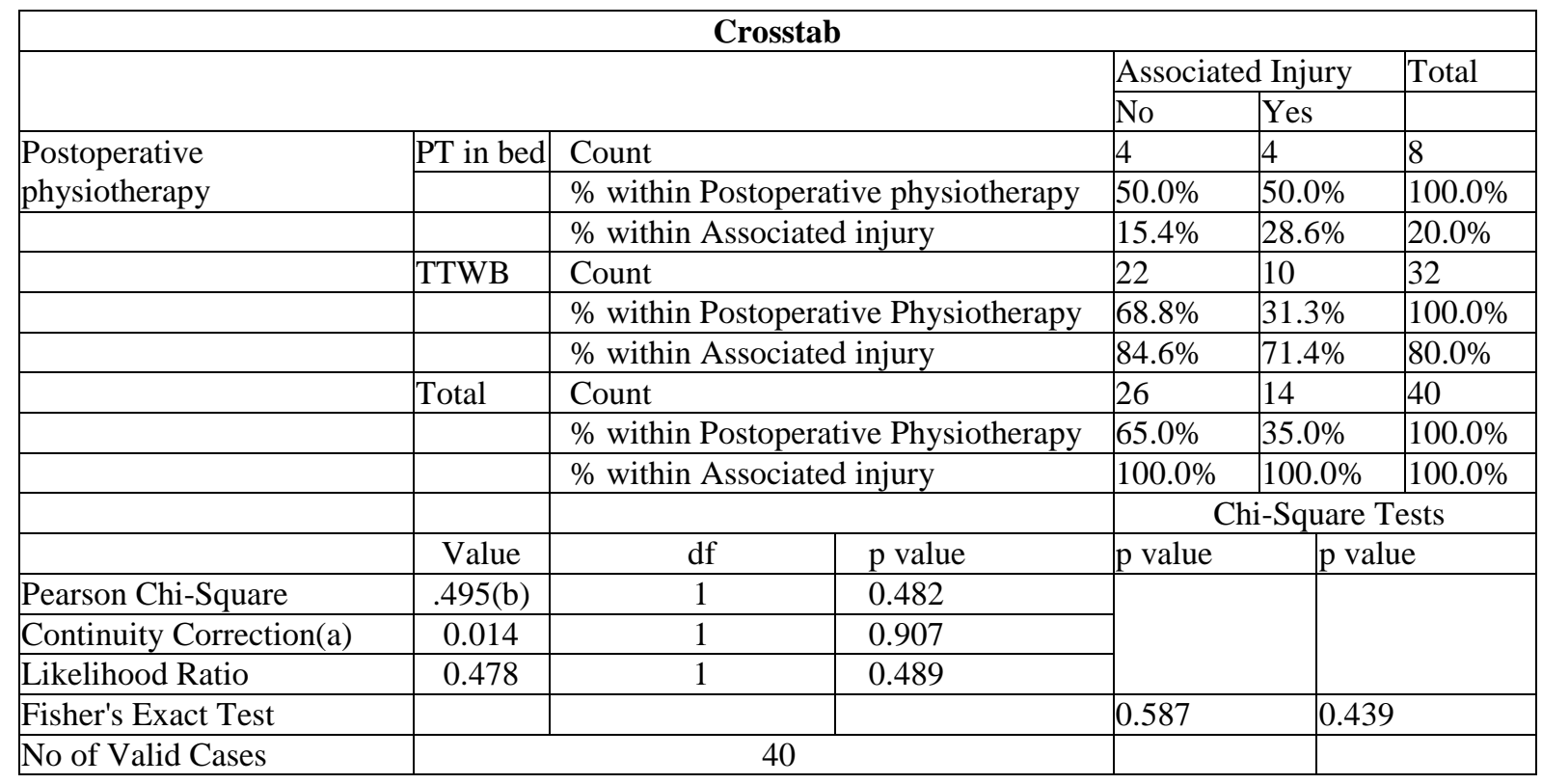

a. Computed only for a $2 \times 2$ table

b. 2 cells $(50.0 \%)$ have expected count less than 5. The minimum expected count is 1.40 .

Table7. Complications In Relation to Associated Injury

\begin{tabular}{|c|c|c|c|c|c|c|}
\hline \multicolumn{7}{|c|}{ Crosstab } \\
\hline & & & \multicolumn{3}{|c|}{ Associated Injury } & Total \\
\hline & & & \multicolumn{2}{|l|}{ No } & \multicolumn{2}{|l|}{ Yes } \\
\hline \multirow[t]{14}{*}{ Complication Penetration } & Medial cortex & Count & 4 & & 0 & 4 \\
\hline & & $\%$ within Complication & $100.0 \%$ & & $0.0 \%$ & $100.0 \%$ \\
\hline & & $\%$ within Associated injury & $15.4 \%$ & & $0.0 \%$ & $10.0 \%$ \\
\hline & mild limping & Count & 2 & & 2 & 4 \\
\hline & & $\%$ within Complication & $50.0 \%$ & & $50.0 \%$ & $100.0 \%$ \\
\hline & & $\%$ within Associated injury & $7.7 \%$ & & $14.3 \%$ & $10.0 \%$ \\
\hline & None & Count & 20 & & 12 & 32 \\
\hline & & $\%$ within Complication & $62.5 \%$ & & $37.5 \%$ & $100.0 \%$ \\
\hline & & $\%$ within Associated injury & $76.9 \%$ & & $85.7 \%$ & $80.0 \%$ \\
\hline & Total & Count & 26 & & 14 & 40 \\
\hline & & $\%$ within Complication & $65.0 \%$ & & $35.0 \%$ & $100.0 \%$ \\
\hline & & $\%$ within Associated injury & $100.0 \%$ & & $100.0 \%$ & $100.0 \%$ \\
\hline & & & & & \multicolumn{2}{|c|}{ Chi-Square Tests } \\
\hline & & & Value & df & \multicolumn{2}{|c|}{$\mathrm{p}$ value } \\
\hline Pearson Chi-Square & & & $1.319(\mathrm{a})$ & 2 & \multicolumn{2}{|c|}{0.517} \\
\hline \multicolumn{3}{|l|}{ Likelihood Ratio } & 1.955 & 2 & \multicolumn{2}{|c|}{0.376} \\
\hline \multicolumn{3}{|l|}{ No of Valid Cases } & \multicolumn{2}{|l|}{40} & & \\
\hline
\end{tabular}

4 cells $(66.7 \%)$ have expected count less than 5. The minimum expected count is .70. 


\section{DisCUSSION}

Percutaneous fixation of acetabular fractures has been published few reports in the orthopaedic literature, mainly fixation of non-displaced or minimally-displaced fractures, most reports focus on the surgical approaches. Improvements in fluoroscopic imaging have facilitated the placement of screws in various methods around the acetabulum. $[10,11,12]$

In 1992 Gay was the first to describe the percutaneous screw fixation technique for acetabular fractures. Their technique involved placing 2 cannulated screws. [13] Starr modified the technique by using 3 screws, he used PSF to stabilize non displaced or minimally displaced $(<2 \mathrm{~mm})$ acetabular fractures. [11] The aim of his technique was to avoid fracture displacement, which would require open reduction and internal fixation, and also to stabilize undisplaced or minimally displaced acetabular fractures in patients with a contralateral injury that required weight bearing.

Percutaneous screw fixation of acetabulum as alternative to traditional open reduction and internal fixation was described in literature. [14, 15] we used the combination of percutaneous screw and plate in 8 patients with transverse acetabular fracture; 6 of them had associated posterior wall fracture and was fixed by posterior plating and augmented anteriorly by anterior column screw (Figure 11) and 2 patient with transverse fracture associated with quadrilateral plate fracture was fixed anteriorly by plating and augmented posteriorly by posterior column screw (Figure 12).

We must be familiar with the 3D anatomy of the pelvis, acetabulum and pelvic radiographic anatomy in multiple planes including inlet, outlet, iliac oblique and obturator oblique views. Norris advocated that intra-operative fluoroscopy was as useful as CT for the evaluation of reduction and confirmation of proper placement of implants However, such imaging is generally available in only one plane at a time and exposes both the patient and the surgeon to radiation, particularly because of the increased soft-tissue mantle and the precise oblique projections necessary for adequate viewing. [17] A technique to lower radiation exposure is by using an off-set guide like an external fixator sleeve specially for anterior column screw where it is difficult to maintain guide wire tip at entry site without sliding down, the surgeon has to keep one hand on the handle and has to maintain the direction of the sleeve while changing the $\mathrm{C}$-arm position to enable guide wire insertion. In our study we found that $\mathrm{C}$ arm is enough for insertion of the screws and failure to maintain the guide wire at the entry site during changing the $\mathrm{C}$ arm position is a major cause to increase operative time and image exposure.

Controlled weight bearing at 2 weeks after PSF has been reported, in other studies total weight bearing was allowed only after 4 weeks. In our study we started protected toe touch weight bearing $2^{\text {nd }}$ day of surgery and full weight bearing at average 8 weeks. In one geriatric patient we started protected full weight bearing $2^{\text {nd }}$ day of surgery, this rather conservative rehabilitation regimen is supported by Starr, which mentioned two elderly patients with minor losses of reduction because of unprotected weight bearing after percutaneous screw fixation.

Percutaneous screw fixation of acetabulum can produce excellent results in selected patients with mildly displaced acetabular fracture and will become an important part of the orthopedic surgeon's tools for the treatment of certain acetabular fractures in the future. [18]

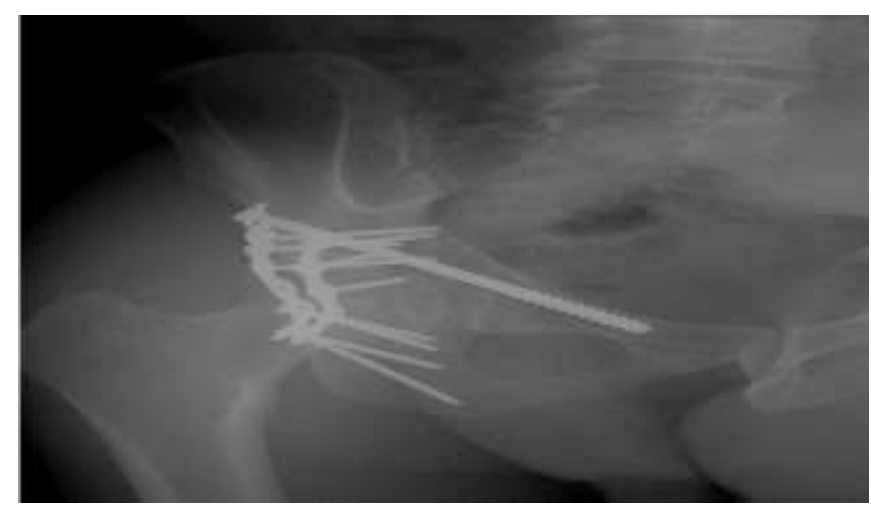

Figure11. Anterioaugmentation of transverse Fracture 


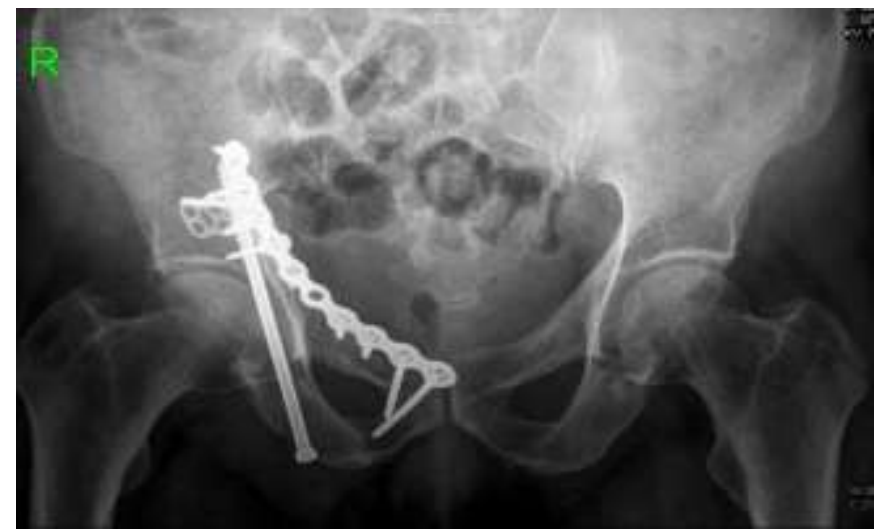

Figure12. Posterior screw for augmentation of

\section{CONCLuSion}

In conclusion, we find that percutaneous screw fixation of acetabular fractures under fluoroscopic guidance is safe and relatively easy surgical procedure for management of noncomminuted and minimally displaced fractures. It has the advantage of allowing early weight bearing, early rehabilitation, pain control and avoiding a second approach in certain situations.

\section{CONFLICT OF INTEREST}

The authors declare that they have no conflict of interest.

\section{REFERENCES}

[1] Giannoudis PV, Grotz MR, Papakostidis C, Dinopoulos H. Operative treatment of displaced fractures of the acetabulum: a meta-analysis. $\mathbf{J}$ Bone Joint Surg [Br] 2005; 87:2-9.

[2] Anthony EB, Frank BW, Justin JM, Richard MA, Cyril M. Percutaneous Fixation of Anterior and Posterior Column Acetabular Fractures. Orthopedics. 2014; 37:675-678.

[3] Giannoudis PV, Tzioupis CC, Pape HC, Roberts CS. Percutaneous fixation of the pelvic ring. J Bone Joint Surg (Br) 2007; 89:145 - 54.

[4] Matta JM, Mehne DK, Roffi R. Fractures of the acetabulum. Early results of a prospective study. Clin Orthop 1986; 205: 241-50.

[5] Xiaoreng F, Sheng Z, Qiang L, Jintao F, Chaowen L, Frankie L et al. Definition of a safe zone for antegrade lag screw fixation of fracture of posterior column of the acetabulum by $3 \mathrm{D}$ technology . Injury, Int. J. Care Injured 2016; 47:702-706.

[6] Arvind VK, Daniel T, Edward KR. Percutaneous Fixation in Pelvic and Acetabular Fractures: Understanding Evolving Indications and Contraindications. Oper Tech Orthop 2015; 25:248- 255 .

[7] Mouhsine E, Garofalo R, Borens O, Wettstein $\mathrm{M}$, Blanc $\mathrm{CH}$, Fischer JF, et al: Percutaneous retrograde screwing for stabilization of acetabular fractures. Injury, Int. J. Care Injured 2005; 36: 1330-1336.

[8] Wolf $\mathrm{H}$, Wieland T, Pajenda G, Vécsei V, Mousavi M. Minimally invasive ilioinguinal approach to the acetabulum. Injury 2007; 38:1170-1176.

[9] Starr AJ, Walter JC, Harris RW, Reinert CM, Jones AL. Percutaneous screw fixation of fractures of the iliac wing and fracturedislocations of the sacro-iliac joint (OTA Types 61-B2.2 and 61-B2.3: or Young- Burgess lateral compression type II pelvic fractures). J Orthop Trauma 2002; 16(2):116-23.

[10] Starr AJ, Reinert CM, Jones AL. Percutaneous fixation of the columns of the acetabulum: a new technique. J Orthop Trauma. 1998; 12:5158.

[11] Bates P, Gary J, Singh G, Reinert C, Starr A. Percutaneous treatment of pelvic and acetabular fractures in obese patients. Orthop Clin North Am. 2011; 42(1):55-67.

[12] Parker PJ, Copeland C. Percutaneous fluoroscopic screw fixation of acetabular fractures. Injury. 1997; 28(9-10):597-600.

[13] Gay SB, Sistrom C, Wang GJ, Kahler DA, Boman T, McHugh N, et al. Percutaneus screw fixation acetabular fractures with $\mathrm{CT}$ guidance: preliminary results of a new technique. Am J Roentgenol. 1992; 4:819-822.

[14] Brown GA, Willis MC, Firoozbakhsh K, Barmada A. Computed tomography imageguided surgery in complex acetabular fractures. Clin Orthop 2000; 370:219-26.

[15] Hammad AS, El-khadrawe TA, Waly AH, Abu- Sheasha GA. The efficacy of posterior plating and anterior column screw fixation in the management of T-shaped acetabular fractures - CART analysis of prospective cohort study. Injury, Int. J. Care Injured 2017; 48(3); 680-686.

[16] Norris BL, Hahn DH, Bosse MJ, Kellam JF, Sims SH. Intraoperative fluoroscopy to evaluate fracture reduction and hardware 
placement during acetabular surgery. J Orthop Trauma 1999; 13:414-417.

[17] Routt ML, Nork SE, Mills WJ. Percutaneous fixation of pelvic ring disruptions. Clin Orthop 2000; 375:15- 29.
[18] Starr AJ, Jones AL, Reinert CM, Borer DS. Preliminary results and complications following limited open reduction and percutaneous screw fixation of displaced fractures of the acetabulum. Injury 2001; 32:4550 .

Citation: Mohamed S. El-Attar, Mohamed Nagy Elalfy, Sherif Aidy. Percutaneous Fixation of Acetabular Fractures by Columnar Screw. ARC Journal of Orthopedics. 2020; 5(2):20-28. DOI:https://doi.org/10.20431/2456-0588.0502004.

Copyright: (C) 2020 Authors. This is an open-access article distributed under the terms of the Creative Commons Attribution License, which permits unrestricted use, distribution, and reproduction in any medium, provided the original author and source are credited. 